\title{
Relaciones e implicancias del determinismo biológico, el pensamiento freudiano de psicología criminal y la nueva criminología
}

\author{
Gino Ríos Patio', a, b, c
}

\section{RESUMEN}

Se analiza el nuevo impulso del determinismo biológico en el momento neoliberal actual, el pensamiento freudiano sobre la psicología criminal y el denominado paradigma científico de la nueva criminología, especialmente el de la criminología crítica, enfocando sus relaciones e implicancias, esto es, las conexiones, contradicciones y consecuencias entre aquellas y estas, con la finalidad de reflexionar sobre las causas de la criminalidad desde su posición criminológica personal. El objetivo del artículo es evaluar la funcionalidad de los enfoques determinista biológico y psicológico de la criminalidad en el actual paradigma científico de la criminología crítica. Como resultado del análisis correlacional, se concluye en que las escuelas de la criminología clínica y psicológica no explican suficientemente la causa de la criminalidad actualmente.

Palabras clave: Determinismo biológico; pensamiento freudiano; nueva criminología; criminología crítica; paradigma científico.

\section{Relationships and implications of biological determinism, the Freudian thought of criminal psychology, and the new criminology}

\section{ABSTRACT}

The author analyzes the new impulse of biological determinism, the Freudian thought of criminal psychology, in the current neoliberal moment and the so-called scientific paradigm of the new criminology, especially that of critical criminology, focusing on their relationships and implications, that is, the connections, contradictions and consequences between those and these, with the purpose of reflecting on the causes of criminality from its personal criminological position. The objective of the article is to evaluate the functionality of the biological and psychological deterministic approaches of criminality in the current scientific paradigm of critical criminology. As a result of the correlation analysis, it is concluded that the schools of clinical and psychological criminology do not sufficiently explain the cause of crime today.

Keywords: Biological determinism; freudian thought; new criminology; critical criminology; scientific paradigm.

1. Director del Instituto de Investigación Jurídica de la USMP.

a. Doctor en Derecho, Doctor en Educación, Maestro de Ciencias Penales, Abogado.

b. Diplomado en Filosofía Política por la Universidad de Harvard.

c. Diplomado en Derechos Económicos, Sociales y Culturales y Derecho a la Educación por la Universidad de Ginebra. 


\section{INTRODUCCIÓN}

La búsqueda de las causas de la criminalidad es, de antiguo, el desvelo de la sociedad y el estado. De eso trata la criminología precisamente, para lo cual sus objetos de estudio son el criminal, la víctima, el crimen y el control social, con fines de proporcionar la información científica válida, contrastable y objetiva que sirva para el diseño de una política criminológica eficaz, que permita prevenir, reducir, controlar y, última ratio, sancionar de manera distinta a la actual, que se caracteriza por retribuir a manera de reacción social vindicativa el castigo; interviniendo positivamente en la cuestión criminal.

En la evolución de la criminología, ciencia social multidisciplinaria y holística, han existido muchas escuelas, corrientes de pensamiento y tendencias criminológicas que han explicado, desde su particular enfoque, la criminalidad, tales como la clínica, la psicológica, la sociológica, la socialista, la norteamericana, la latinoamericana, la crítica, el realismo de derecha, el realismo de izquierda, entre otras.

De acuerdo con los postulados de dichas escuelas, se puede distinguir claramente dos fases históricas en la criminología, una la criminología clásica, marcadamente positivista, preocupada por el paradigma etiológico, es decir, por la búsqueda de las causas del crimen en el individuo; y otra la nueva criminología, especialmente crítica del antiguo pensamiento, interesada en el paradigma científico, esto es, en el proceso de criminalización, atributo del poder político, como el origen del crimen. No se crea, sin embargo, que aquella era apolítica, mientras que ésta es política. De ninguna manera, ambas tienen un énfasis político en el sentido prístino del término, porque están ocupadas en el mantenimiento o transformación, respectivamente, del statu quo.

Lo anterior no obstante, es importante confrontar el pensamiento y los aportes de las distintas escuelas criminológicas para acercarnos más a las causas de la criminalidad, pues ésta representa el problema número uno del país y afecta directamente a uno de los dos fines esenciales del estado, como es la seguridad integral; ergo perturba y dificulta el cumplimiento del otro fin estatal, que es el bienestar general, pues ambos son conceptos complementarios e interdependientes. Estos objetivos justifican plenamente la realización de este estudio comparativo.

En el presente artículo se examina el enfoque biológico y psicológico en la criminología de cara al pensamiento de la nueva criminología y, en especial, de la criminología crítica, con la finalidad de conocer cuáles son las implicancias de aquellas maneras de entender el origen del crimen con los postulados de la nueva criminología.
En esa línea, se examina en la segunda parte las causas genéticas del crimen y el pensamiento de Sigmund Freud sobre la violencia; en la tercera parte se desarrolla el nuevo planteamiento criminológico; en la cuarta parte se analiza el enfoque crítico de la criminología, para exponer en una quinta parte cuáles son las implicancias de este análisis correlacional, para finalmente arribar a la conclusión de que la criminología clínica y la psicológica no explican suficientemente la causa de la criminalidad actualmente.

\section{El determinismo biológico}

En el campo de la biología, filosofía y sociología, el determinismo postula que la conducta humana es definida y controlada por los genes individuales, esto es, resulta un producto de la carga hereditaria y del factor innato. Ellos definen nuestra capacidad, maneras de responder y posibilidades de desarrollo.

En la actualidad es posible secuenciar un genoma identificando los seis millones de bases que definen el ADN de una persona, con lo cual accedemos a información genética detallada, así podemos ayudar a prevenir enfermedades y fallas o a minimizar su impacto. Pero eso no es todo, estos nuevos conocimientos permiten estudiar las bases moleculares de la regulación genética e identificar nuevos y sorprendentes actores, como el ARN no codificante y las modificaciones de la cromatina, según Pankaj Mehta ${ }^{(1)}$, quien además señala que para entender la razón de una serie de comportamientos humanos, tales como la guerra, la violación sexual, el terrorismo internacional, entre otros, el determinismo biológico nos recuerda que existen genes causantes.

¿Quién tiene acceso a esta revolucionaria información genética? ¿Dicha información sirve para justificar la adopción de acciones violentas contra personas o etnias consideradas peligrosas? ¿Estamos ad portas de otra "solución final" del tipo holocausto? ¿O pasa inadvertido el "genocidio por goteo" del que nos avisa el maestro Zaffaroni?.

La ciencia desarrolla estadísticas para analizar una inmensa cantidad de datos de secuencias genómicas de poblaciones de todo el mundo. Los humanos nos diferenciamos solamente en el $0,1 \%$ del $A D N$, sin embargo, este ínfimo porcentaje origina variaciones entre los individuos, por lo que es posible relacionar una variante genómica con un rasgo o enfermedad concretos.

Sin embargo, no es posible negar que los fenotipos, desde la estatura y el color de los ojos hasta enfermedades como la diabetes, surgen de interacciones complicadas entre los genes múltiples y el medio ambiente; lo cual nos 
debe obligar a asumir un deber de cautela y prudencia sobre la posibilidad y cómo la información suministrada por la ciencia genética molecular puedan aplicarse a la determinación de las causas de la criminalidad.

Si bien no es posible negar que los elementos constitutivos básicos de un organismo están codificados en su material genético seleccionado por la variabilidad derivada del proceso de evolución; afirmar que la conducta humana, desde no ser cortés en responder un saludo hasta asesinar a una persona, responde a un conjunto determinado de genes, resulta ser un ejercicio de generalización sospechoso.

¿Cómo explicar las contradicciones estructurales del capitalismo y el neo liberalismo? ¿Cómo exponer razonablemente la concreción de los principios democráticos de igualdad, libertad y fraternidad a nivel mundial, en medio de una reducida élite que acopia ingentes cantidades de riqueza y la inmensa cantidad de personas que se sume en la extrema pobreza? ¿Cómo entender el hecho de que en el momento estelar de los derechos humanos en occidente, en el que se han alcanzado su constitucionalización y universalización, un alarmante crecimiento del índice de criminalidad en los países periféricos?

Si ponemos énfasis en explicar genéticamente el comportamiento humano, entonces se ocultan las causas estructurales de índole económica, social y político que dirigen la criminalización a determinados grupos humanos, así como se esconde el ejercicio selectivo del poder punitivo, con lo cual se justificaría el dominio, la opresión y la desigualdad, repitiendo discursos de épocas que se creían superadas. Pretender explicar el crimen a partir del estudio, diagnóstico y tratamiento personalizado del delincuente, como sostiene Ríos. G. ${ }^{(2)}$ supone considerar que el crimen es una conducta anómala, propia de una persona enferma, lo cual está muy lejos de la libertad con la que procede un infractor al momento de decidir criminalizar su comportamiento. Por eso, la criminología crítica, incrédula del determinismo biológico, considera que en materia de cuestión criminal, el pasado absolutista e inquisitivo nunca se fue de nuestra sociedad, permaneció con otros ropajes y peroratas que disfrazaron su identidad.

\section{El pensamiento freudiano}

La nueva criminología conceptualiza el crimen como un conflicto interpersonal o contra la sociedad, en el que interviene la violencia y que se problematiza al no encontrar solución temprana.

Respecto de los conflictos violentos Freud ${ }^{(3)}$ sostiene en la misiva de respuesta a Einstein sobre el porqué de la guerra, que esta implica una beligerancia física que se origina en un conflicto violento, el cual se produce porque el humano, como los animales menores, usa la fuerza para dirimir un conflicto, convirtiéndolo en violento. Las modalidades empleadas para el uso de la fuerza son accesorias y sucesivas, esto es, el uso de la fuerza muscular, el de las armas o el de la inteligencia. Pero el objetivo perseguido es siempre el mismo, destruir al enemigo. La finalidad no puede ser otra que la de impedir que ese enemigo $u$ otros se vuelvan a oponer. Evidentemente, se trata de lo que en derecho penal se conoce como prevención especial, la dirigida al propio autor de la infracción; y prevención general, la destinada implícitamente a terceros.

Es un hecho, entonces, que muerto, atemorizado u obligado a realizar tareas "útiles" a la sociedad, el enemigo queda sometido. Pero en esta sumisión del enemigo, Freud registra el hecho de que el poderoso pierde una porción de seguridad, debido al temor que acumula por el deseo de venganza que el castigo que inflige puede despertar -y de hecho despierta- en el enemigo.

Hasta aquí, el pensamiento de Freud puede perfectamente encajar en el planteamiento de la nueva criminología y de la criminología crítica, pues éstas encuentran la causa del crimen en el poder de criminalización, esto es, en el poder punitivo del estado, en manos de los grupos dominantes.

Más aun, Freud considera que a partir del reconocimiento de que la fuerza mayor de un individuo puede ser compensada por la asociación de varios más débiles, la violencia es vencida por la unión, es decir, aparece el derecho de la comunidad para enfrentar al individuo que se le opone. Empero, la unidad de la comunidad debe ser permanente para que prevalezca el derecho, de lo contrario, quien se sienta más fuerte tratará de ejercer su poderío y, con ello, hacer prevalecer su voluntad sobre el derecho.

Freud es consciente, sin embargo, de la existencia de desigualdades de poder, lo que le hace sostener que en ello se origina el dominio de unos sobre otros, inclusive y fundamentalmente en la elaboración de leyes, desmantelando así el dominio del derecho y retornando el dominio de la violencia.

Este extremo del pensamiento freudiano debe haber hecho reflexionar al insigne psicoanalista, acerca de si valió de algo la experiencia histórica de que cada uno de los miembros de la sociedad haya renunciado a una cuota de su libertad personal en pro del derecho, el cual es producto del estado, que el hombre crea a través del mito liberal del contrato social. Pues termina afirmando que si bien una sociedad está unida por dos factores de identificación, que son la violencia y los lazos afectivos, cualquiera de ellos deberán manifestar una comunidad de intereses para llegar a ser trascendentes. Esta reflexión 
puede explicar por qué en los países cuya identidad nacional es inexistente o precaria, la violencia sobresale por encima del derecho.

Lo anterior lleva al célebre psicoanalista a considerar que en una misma comunidad no se puede evitar los conflictos violentos de intereses. Es decir, el crimen, cuya definición criminológica es, justamente, un conflicto de intereses interpersonal o con la sociedad, en el que interviene la violencia y que se problematiza o agudiza sin encontrar solución en su evolución; es algo natural y omnipresente en una sociedad, como afirmara Emile Durkheim, concepto que repite Pavarini, $\mathrm{M}^{(4)}$.

La mejor forma alternativa de solucionar los conflictos, según Freud, son el reconocimiento y predominio de las necesidades y los fines comunes, que derivan de la coexistencia en la misma comunidad, ante lo cual se impone consensualmente un nuevo orden social y jurídico. De hecho, para Freud el derecho surgió de la fuerza precisamente como límite a ésta, de modo que un nuevo orden jurídico puede equilibrar la relación social y reducir la violencia, aspecto este que coincide también con uno de los planteamientos de la criminología crítica.

La teoría de los instintos, que ha llegado a elaborar gracias a sus investigaciones psicoanalíticas, es para Freud otra causa de la criminalidad. Esta teoría binaria reconoce dos clases de instintos, que son los eróticos que unen y conservan; y los tanáticos que agreden, destruyen y matan. Con ambos se expresa la vida. Ninguno se presenta solo, sino acompañado de su contrario. Felizmente, Freud se cuida de advertir que no se introduzca los conceptos de bueno y malo. Esta precaución es compartida por la criminología crítica, como veremos más adelante.

La teoría esbozada se complica cuando Freud sostiene, en adición a la manifestación bipartita antes indicada, que es insólito que una conducta obedezca a un único instinto. Siempre hay una cantidad apreciable de motivos, nobles o ruines, entre los que se ocultan y los que no. De hecho, estímulos ideales sirvieron de pretexto y de refuerzo inconsciente para ambiciones destructivas. La historia está plagada de ejemplos tristemente célebres.

El instinto de muerte, para Freud, se convierte en instinto de destrucción cuando, con la ayuda de órganos especiales, es dirigido hacia afuera del individuo, lo que permite deducir que el hombre defiende su vida destruyendo la vida ajena. Sin embargo, una parte del instinto de muerte se mantiene activo en el interior del ser, lo que puede ayudar a explicar la formación de la conciencia moral del hombre. El problema se agudiza cuando el instinto agresivo se dirige al exterior, pues ello alivia al hombre y le causa una sensación de beneficio.

En torno a la prevención de la criminalidad, Freud se centra en la vinculación afectiva, la cual puede producirse por amor y por identificación de intereses. De esta forma, se puede desviar el instinto agresivo-destructivo y sublimar la energía en otras expresiones. Sobre el mismo tema preventivo, el pensamiento freudiano destaca la existencia de dirigentes y dirigidos en la sociedad, sugiriendo educar a los hombres dirigentes para que sean independientes, inaccesibles a la intimidación, busquen la verdad y estén dirigidos por la razón y no por la pasión. Pero claro, advierte que el poder se opone a este sistema educativo, el cual podría construir una unidad tan resistente de los hombres, aunque no existieran vínculos afectivos entre ellos. Otra relación con la nueva criminología, pues ésta sostiene en su vertiente crítica, que el dominio del poder busca, por todos los medios a su alcance, mantener el statu quo, por lo que es fácil suponer que un sistema educativo destinado a formar ciudadanos críticos, no sería bien visto por el poder.

Finalmente, acerca de la civilización, a la que le debemos todo cuanto la humanidad ha progresado, pero también lo que sufrimos, Freud considera que limita las tendencias instintivas y fortalece el intelecto. Sin embargo, en este punto no hay concordancia con el pensamiento crítico en criminología, pues el progreso de la civilización, que demuestra el avance de la intelectualidad del hombre, a su vez se utiliza para sofisticar la criminalización de conductas y la punición de las mismas, en un ejercicio perverso de la dominación y el control social, como veremos más adelante.

\section{La nueva criminología}

De antiguo se afirmaba que los hombres pueden cometer delitos por ser egoístas por naturaleza. De ahí surge la necesidad en la sociedad de formar un consenso para proteger la propiedad privada y el bienestar de todos. Esta necesidad los lleva a celebrar libremente un contrato con el estado para salvaguardar la paz, en virtud del cual se le atribuye el poder de sancionar mediante una pena a quien comete violaciones de los intereses ajenos.

Como se puede apreciar, este planteamiento clásico suponía que existía un consenso entre los hombres acerca de la inevitabilidad del statu quo axiológico y material; y que un comportamiento ilegal era básicamente anómalo y patológico. Sobre esta base, la antigua criminología justificaba el control social de los comportamientos desviados, lo que permitía atribuir caracteres positivos o negativos a las conductas, de acuerdo con su utilidad en medio de una sociedad fundada en la propiedad privada. Esta visión criminológica clásica no percibía que si el derecho de propiedad privada era un motivo para el robo, el delito no podía ser irracional.

Contrariamente, la criminología positivista afirma que el criminal se revela automáticamente a través de su 
conducta, impulsado por dos fuerzas de las que no tiene conciencia. Es decir, el criminal, según la criminología positivista, no tiene conciencia de su comportamiento. Así, al igual que en el clasicismo, la criminología positivista se concentra en el individuo que delinque y no en el acto delictivo, para encontrar en él la causa del crimen.

Cabe preguntarse entonces ¿El hombre solo se adapta o reacciona? Los niveles de creatividad humana y de cambio social parecen desmentir una eventual afirmación en ese sentido.

Los antecedentes de los postulados de la nueva criminología hay que encontrarlos, según el ensayo Criminología Crítica de González Ascencio ${ }^{(5)}$, en la criminalidad conectada con la propiedad privada y la crítica al sistema penal, idea postulada por Tomás Moro; la desigualdad de las condiciones sociales como causa de crímenes, tendencia sostenida por G. B. De Mabl; la relación entre el crimen y un orden social que permite vivir a un hombre en la abundancia y a otro en la más absoluta miseria, línea acotada por Godwin; y la vinculación entre sistema económico y crimen de Turati.

Los aspectos centrales de la nueva criminología, como lo señalan Taylor, I., Walton, P. y Young, J. ${ }^{(6)}$ son, en primer lugar, que la causa de la criminalidad no está en el individuo, en una supuesta anormalidad biológica o anomalía psíquica o psicológica, sino en el poder de criminalización, es decir, en el ejercicio de control y punición que hace el estado respecto de qué es un comportamiento criminal, quién es criminal y dónde y cómo debe cumplir la pena que se le impone. En segundo lugar, postula que son las estructuras sociales, económicas, políticas y culturales las que conforman una situación de injustas desigualdades materiales y de posibilidades en la que transcurre la vida de la mayoría de las personas, por lo que la causa del delito está indisolublemente ligada con la forma de los ordenamientos sociales de la época, que están basados en la diferencia de rango o de poder, que generan desigualdad.

Los intereses, valores, orientaciones y normas en una sociedad, son determinados principalmente por el orden político, que maneja la distribución del poder y la autoridad; el orden económico, que señala la producción de bienes y servicios; el orden educacional, que administra el aprendizaje formal de las personas en la sociedad; y por el orden público, que gobierna la protección y el mantenimiento de la sociedad. En cada uno de ellos existen fracciones identificadas por el reconocimiento común de un interés que buscan satisfacer.

Es claro, entonces, que el derecho en general, y el derecho penal en particular, está relacionado con la coalición entre el capital y el Estado. Ergo, el comportamiento considerado delictuoso y la facultad de imponer penas están sólidamente vinculadas con el control del Estado.
En efecto, el crimen es, siempre, el comportamiento considerado problemático en el marco de esos ordenamientos sociales; por tanto, para que el delito sea extinguido esos ordenamientos deben cambiar esencialmente. La desviación es normal en tanto y en cuanto represente la diversidad humana, grupal, social.

De esta manera, comprender que el derecho formal está vinculado con la alianza entre el capital y el Estado, es percibir que la sanción del comportamiento como delictuoso y la posibilidad de imponer penas están fundamentalmente relacionadas con el control del Estado.

En definitiva, la nueva criminología afirma que las formas de comportamiento en sí mismas no diferencian a los criminales de los no criminales, sino las respuestas de los miembros convencionales, acríticos y conformistas de la sociedad, que identifican e interpretan el comportamiento como desviado. La desviación no es, pues, una cualidad intrínseca del mismo acto, sino algo que la sociedad le atribuye, etiquetando y estigmatizando a las personas como desviadas.

\section{La Criminología Crítica}

Esta escuela criminológica perteneciente a la nueva criminología, se apoya en los fundamentos de ésta, que configuran la nueva teoría de la desviación, tales como el disenso y no el consenso social; el carácter diverso del comportamiento considerado desviado; la naturaleza racional y política del delito, no patológica; la mayor gravedad de los crímenes cometidos por las minorías; la normalidad del delito y no su anormalidad; $y$ el intervencionismo positivo o anti intervencionismo en lugar del correccionalismo, entre otros, para aplicar planteamientos marxistas, haciendo ver que el estado personifica los intereses de una clase dominante, ya no de grupos sociales; y que las estructuras económicas forjan la contradicción entre el trabajo y el capital, ya no el conflicto; por lo que propone una transformación del contexto social, ya no el tratamiento correccional.

Larrauri, E. ${ }^{(7)}$ acota que, por efecto de la incorporación de los postulados marxistas, la criminología crítica esquematizó el legado de la nueva criminología afirmando que la sociedad no es consensuada ni conflictiva, sino que está gobernada por una clase dominante; los intereses de esta clase están contenidos y son protegidos por el derecho penal, el que debiera salvaguardar los intereses de la población; las agencias de control penal también protegen dichos intereses, no por su legitimidad, pues no la tiene, sino por la coerción o la difusión de una falsa conciencia; los crímenes son definidos como los comportamientos que amenazan o dañan los intereses de dicha clase y así obtienen el apoyo de las instituciones del estado, como por ejemplo en la imposición de penas graves y desproporcionadas. 
Se advierte en el discurso criminológico crítico que la causa del crimen pasa a ser el capitalismo, sistema económico altamente criminógeno que conlleva una estructura social profundamente desigual, exaltadora del ello o id y detonadora de un exacerbado individualismo que termina con la solidaridad social.

Esta búsqueda de la causa del crimen en el poder político, más propiamente en el ejercicio desigual y abusivo del control social formal e informal, destaca la visión macroscópica del análisis de la cuestión criminal, por encima de la lectura microscópica que tenía la criminología positivista clínica y psicológica, la cual no consideraba el examen socio político.

\section{Relaciones e implicancias}

Entre el pensamiento freudiano de psicoanálisis criminológico y la nueva criminología y la criminología crítica, encontramos relaciones e implicancias, como son, en primer lugar, la existencia de un conflicto violento en la base del comportamiento criminal, el cual es un dato común entre el pensamiento freudiano y la nueva criminología, aun cuando dicho conflicto se genere por causas diferentes, en un caso, los instintos; y en el otro caso, las estructuras sociales, determinadas por el factor económico, que el estado y sus instituciones políticas, traducen en situaciones de injusticia y desigualdad.

Sin embargo, la dualidad de poderes entre la fuerza (poder) y el derecho que Freud considera, la nueva criminología no entiende a éste como límite de aquella, sino más bien como un vehículo o instrumento para mantener su posición dominante y el statu quo.

El pensamiento de Freud coincide con la nueva criminología en que la finalidad de la fuerza (poder) es siempre el mismo, destruir o someter e inocuizar al enemigo, para lo cual crea uno con el propósito de legitimar su accionar a través del discurso racionalizador del sistema penal. Zaffaroni, E. ${ }^{(8)}$ sostiene que el modelo penal se vuelve una técnica gubernamental que invade toda la vida social y amenaza la democracia. Al fabricar enemigos y penándolos neutraliza cualquier obstáculo al poder punitivo limitado.

En ese sentido, Pavarini, M. (op. cit.) anota que en el período comprendido del siglo XVI al siglo XVIII, se genera un proceso de profundos cambios económicos-sociales que llevan a transformar el modelo de producción feudal en uno de producción capitalista; y consecuentemente se quiebra el viejo orden sociopolítico y se instaura otro con la clase burguesa en el rol dominante, de modo tal que se presta atención a las nuevas formas de desobediencia, disenso, no integración y violación de las leyes y, en ese sentido, la preocupación del nuevo orden era cómo educar y disciplinar a los no propietarios a aceptar como natural su condición de proletarios $\mathrm{y}$, por ende, a garantizar que no desarrollen conductas atentatorias contra los bienes ajenos. El momento crítico de las contradicciones del sistema de producción capitalista y las exigencias de racionalización, posibilitó la idea proletario-pobrecriminal; lo cual evidentemente trasciende a una mera explicación etiológica basada en el positivismo biológico o el determinismo psicológico.

A mayor abundamiento, Palacios, G. ${ }^{(9)}$ expresa que el discurso y el sistema jurídico penal es falso porque la normatividad es ideal, dirigido a la justicia y la proporcionalidad de las penas, entre otros aspectos, mientras que la operatividad real es draconiana desde que aplica penas extremas y abusa del encarcelamiento, lo que constituye características de un tratamiento a un enemigo que a un semejante. Añadimos que en la actualidad, en nuestro país, el derecho penal simbólico, el derecho penal del enemigo y el populismo penal están en pleno apogeo, con lo que se confirma la apreciación de Zaffaroni, Pavarini y Palacios.

Respecto a este punto, el determinismo biológico no es concurrente. En efecto, si bien no es posible negar que la herencia genética puede manifestarse en un súbito incremento de la presión sanguínea o el trastorno del ritmo cardíaco frente a un estímulo externo, eso no significa que sea la causa del comportamiento criminal subsecuente, sino acaso una condición.

La criminología crítica responde a los determinismos biológico y psíquico en el sentido que la relación naturaleza y cultura es una característica fundamental del ser humano, en la medida que marca lo que somos y hacemos. Por ello, el ejercicio del poder político que es una forma cultural de la sociedad, crea estructuras conflictivas que producen ciudadanos conflictivos, de cuya interacción emerge la violencia y la criminalidad.

El pensamiento freudiano de que el objetivo perseguido es siempre el mismo, de destruir al enemigo, impidiendo que ese enemigo $u$ otros vuelvan a oponerse al sistema, lo que viene a ser la prevención penal general y especial; no se condice con la determinación psicológica hacia el crimen, pues la violencia empleada contra el enemigo no resulta eficaz, ya que el estado no resocializa, reeduca ni rehabilita al criminal, que según la criminología psicológica habría incurrido en un comportamiento criminal debido a la hipertrofia de su Ello o Id y a la expresión de su instinto tanático.

Entonces, como no se ha podido "curar" o "normalizar" al criminal, la sociedad lo considera incorregible y lo excluye hacia adentro relegándolo a prisión vía la aplicación de penas excesivas. Como se puede advertir fácilmente, esta postura de la criminología psicológica, no resiste un análisis serio de la cuestión criminal. 
La criminología crítica comparte el criterio de Freud respecto a la existencia de desigualdades de poder, lo que origina el dominio de unos sobre otros, arruina la primacía del derecho y permite la hegemonía de violencia; y también la posición que adopta sobre la inevitabilidad del crimen por su normalidad. De ahí surge precisamente el fundamento de la prevención.

Respecto a ello, Freud se centra en la vinculación afectiva, la cual puede producirse por amor e identificación de intereses; siendo necesario la formación de dirigentes y dirigidos en la independencia, la búsqueda de la verdad por medio de la razón y no por la pasión; y advierte que el poder se opone a esta educación. Este planteamiento es compartido por la criminología crítica, para la cual la violencia estructural, generada por el capitalismo y exacerbada por el neo liberalismo, manifestada en la miseria, la desigualdad y la exclusión social, es la causa de la criminalidad y la consecuencia del programa de dominación social.

Sobre el particular, el determinismo genético tampoco concurre en este punto, pues las enfermedades orgánicas y trastornos psíquicos innatos estigmatizan socialmente al hombre y lo convierten en un sujeto pasible de exterminio o internamiento clínico, según el poder político, es decir, nada más alejado de la condición de dignidad humana.

Según Seguí, L. ${ }^{(10)}$ Freud se adhiere a la teoría contractualista, según la cual hay un hipotético pactum societatis por el que los hombres aceptan convivir sin asesinarse unos a otros, seguido del pactum subjectionis, por el que ceden el monopolio de la violencia a una autoridad investida de poder. Con base en este pensamiento, Freud asevera que el hecho constitutivo de la incomodidad de la relación del hombre con la ley es la misma ley que se impone estructuralmente, como la representación alegórica del discurso del amo. De esta manera, el orden jurídico resultaría ser un experimento para evitar la extinción de la especie, pero al mismo tiempo liquida los instintos tanáticos con la venganza de la ley penal. Sin embargo, cabe observar cuán potentes son las pulsiones del hombre que la violencia y el crimen persisten históricamente y en muchos países, como el nuestro, con marcada tendencia a incrementarse.

El análisis comparativo del pensamiento freudiano y de la criminología critica, nos lleva a plantearnos si la causa del crimen es objetiva o subjetiva, esto es, si subyace en el interior del individuo o si, por el contrario, se le encuentra en el poder político y las estructuras sociales y económicas. Es posible aseverar, en todo caso, que el primero ayuda a indagar en el inconsciente sacudido o alienado por el neoliberalismo, la globalización y la tecnología que están formando un hombre irreflexivo, conformista, acrítico, funcional, lo que permite comprender que la causa del crimen es esta última. Como afirma Ríos, G. (op. cit.) buscar las causas del crimen en la estructura de la sociedad es hacer etiología social, de índole macrológica y no micrológica, que analice a la sociedad como objeto y no como medio.

Lo insólito es que la sociedad exige al individuo que canalice sus impulsos agresivos en virtud de las reglas sociales y las normas penales, fortaleciendo el Superyó para que la conducta individual sea dirigida por la conciencia moral, sin embargo la voracidad lucrativa empresarial, la ambición desmedida de poder de las clases dominantes y la desinformación y deformación de la realidad por parte de los medios de comunicación, demuestran que la violencia es cotidiana y está en todas partes, de manera personal, así como estructural, razón por la cual el psicoanálisis puede ser visto como una herramienta fundamental para comprender los comportamientos humanos, así como un instrumento de transformación que proponga al hombre el cambio del estado de las cosas, tanto a nivel individual cuanto en el plano social, partiendo de una toma de conciencia de la realidad, para propiciar su evolución.

En definitiva, como anota Palomero, J. ${ }^{(11)}$ el ser humano es sumamente complicado y su comportamiento requiere elucidaciones interdisciplinarias, multifactoriales y pluricausales, pues el control de nuestro organismo depende de nuestros genes y circuitos neuronales, como también de los procesos dialécticos de la historia y la cultura; de nuestros propios intereses, aspiraciones y posibilidades; de nuestros pensamientos, estímulos y creencias; de nuestros propios impulsos e instintos; y del resultado de múltiples mecanismos y procesos de comunicación e interacción personal y social, factores todos estos que resultan activados por causa de la desigualdad e injusticia estructurales en una sociedad, situación que de acuerdo con la nueva criminología y la criminología crítica, genera la criminalidad.

En conclusión, Sigmund Freud considera que el crimen (conflicto violento) tiene su causa en la base del inconsciente, en donde moran los instintos y deseos más profundos del ser humano, así como la función que la ley cumple en él.

Este determinismo psíquico difiere del determinismo biológico (criminología positivista clínica) porque en este último la causa del crimen obedece a causas orgánicas, mientras que en aquel obedece a una determinación del inconsciente. En ese sentido, un comportamiento criminal puede ser explicado como el producto de toda la vida de la persona que lo perpetra.

Sin embargo, los impulsos tanáticos, que son universales, no hacen a todos criminales, por lo que es indispensable 
encontrar la causa anterior que hace detonar dichas pulsiones. Asimismo, cabe relievar que los caracteres genéticos no reducen a la persona a ser un predestinado para el crimen, acaso solamente podría indicar la existencia de cierta inclinación o pre disposición a determinados comportamientos, los cuales serán criminalizados en función de lo que decida el poder punitivo.

La nueva criminología en general y la criminología crítica en particular, coinciden con el pensamiento freudiano en algunos aspectos desarrollados a lo largo del presente artículo, mas no en el determinismo del inconsciente como causa del crimen, que es lo fundamental en dicho pensamiento, pues sostienen que las injustas estructuras económicas y sociales, que conllevan desigualdad, miseria y segregación, y que son producto de la dominación ejercida por una clase social sobre las demás, constituyen la causa final del crimen, que hace saltar los instintos tanáticos.

En conclusión, las relaciones entre la psicología criminal de Freud y la nueva criminología se dan, básicamente, en la naturalidad y normalidad del conflicto violento entre los hombres; en la existencia del poder como factor de dominación social; y en la necesidad de vincular afectivamente $\mathrm{o}$ identificar por medio de intereses comunes a los hombres; pero son implicantes respecto a la subjetividad (criminología psicológica) u objetividad (nueva criminología) de la causa del crimen; la existencia de consenso social (criminología psicológica) o de conflictividad social (nueva criminología); y las diferencias fundadas en desigualdad, discriminación y miseria, entre los fines económicos, exitistas y materialistas que la sociedad impone subliminalmente a los hombres y los medios legítimos que prevé y normativiza para alcanzarlos; mientras que no existen puntos de encuentro entre el determinismo biológico y la criminología crítica. No obstante, independientemente de la clase de estado, democrático, totalitario o autoritario; y del tipo de régimen económico, capitalista o socialista, la criminalidad continuará existiendo como producto de relaciones desiguales en la interacción entre los hombres; resultado de la naturaleza humana y del medio externo; y del ejercicio arbitrario del poder punitivo.

\section{REFERENCIAS BIBLIOGRÁFICAS}

1. Mehta P. El resurgimiento del determinismo biológico en la era neoliberal [Internet]. Sin permiso: sin permiso.info; 2014. Disponible en: http://www.sinpermiso.info/textos/ el-resurgimiento-del-determinismo-biolgico-en-la-eraneoliberal.

2. Ríos G. La herencia de la criminología clínica. Horiz Med. 2017;17(2): 71-6.

3. Freud, S. ¿Por qué la guerra?. Obras completas.1932; 22, 1932-6.

4. Massimo P. Teorías criminológicas burguesas y proyecto hegemónico. En: Control y dominación.9 a impresión. Argentina: Siglo XXI; 2010.

5. González G. Criminología critica. En: Formación pericial con perspectiva de género. Mexico: Universidad Nacional Autónoma de México;2-22.

6. Taylor I, Walton P, Young J. La nueva criminología: contribución a una teoría social de la conducta desviada. $2^{\mathrm{a}}$ ed. Argentina: Amorrortu; 1997.

7. Larrauri E, Larrauri E. La herencia de la criminología crítica. $2^{a}$ ed. Mexico D.F.: Siglo XXI; 2009.

8. ZaffaroniE. Lacuestióncriminal. $6^{\mathrm{a}}$ ed. Argentina:Planeta;2011.

9. Palacios G. Criminología contemporánea: Introducción a sus fundamentos teóricos. $1^{\text {a }}$ ed. México: Instituto Nacional de Ciencias Penales; 2014.

10. Seguí L. Sobre la responsabilidad criminal: Psicoanálisis y criminología. $1^{\text {aed. }}$ Madrid: Fondo de Cultura Económica; 2012.

11. Palomero J, Fernández M. La formación del profesorado ante el fenómeno de la violencia y convivencia escolar. Revista Interuniversitaria deFormación del Profesorado.2002;44:15-35.

Fuentes de financiamiento:

Este artículo ha sido financiado por el autor.

Conflictos de interés:

El autor declara no presentar ningún conflicto de interés.

\section{Correspondencia:}

Gino Ríos Patio

Dirección: Av. Alameda de la Molina Vieja 695 Dpto.03. La Molina. Lima, Perú

Teléfono: 997974318

Correo electrónico: griosp@usmp.pe

Recibido: 15 de junio de 2017

Evaluado: 21 de junio de 2017

Aprobado: 21 de agosto de 2017

( $)$ La revista. Publicado por Universidad de San Martín de Porres, Perú. (cc) $\mathbf{B r}$ Licencia de Creative Commons Artículo en acceso abierto bajo términos de Licencia Creative Commons Atribución 4.0 Internacional. (http://creativecommons.org/licenses/by/4.0/) 